\title{
Antioxidant Activity of Leaf Extract of Aegle marmelos Correa ex Roxb.
}

\author{
Sachin Kumar ${ }^{1 *}$, Ramesh B. Bodla², Himangini Bansal ${ }^{2}$ \\ 'Department of Pharmacology, DIPSAR, New Delhi, INDIA. \\ 2Department of Pharmaceutical Chemistry, DIPSAR, New Delhi, INDIA.
}

\begin{abstract}
Introduction: Leaf extracts of Aegle marmelos are reported to have hypoglycemic and anticancer effects. While a lot of information is available about the antioxidant activity of fruit of $A$. marmelos not much information is available about the antioxidant activity of the leaf of $A$. marmelos. Objective: The primary objective if this study was to ascertain the antioxidant activity of leaf extract of $A$. marmelos (AME). Methods: AME was evaluated for total phenolic content (TPC) and total flavonoid content (TFC) by Folin-Ciocalteau reagent method and by aluminium chloride method, respectively. Antioxidant activity of AME was assessed by FRAP assay, DPPH assay, ABTS cation scavenging activity and by reducing power determination. Results: High levels of TPC and TFC were found in AME which showed antioxidant activity comparable to vitamin C. Significant correlation
\end{abstract}

between TPC, TFC and antioxidant activity of AME was found when Pearson's correlation is applied. Conclusion: This study proved that the leaves of $A$. marmelos have high antioxidant component.

Key words: Aegle marmelos, Cation scavenging, Free radical scavenging, Reducing power.

Corresponding author: Sachin Kumar, Department of Pharmacology, DIPSAR, Sec-III, Pushp Vihar, M B Road, New Delhi-110017, INDIA.

Tel no: 9911214573

Email: sachinsodan@gmail.com

DOI : 10.5530/pj.2016.5.6

\section{INTRODUCTION}

Aegle marmelos is a medium size perennial tree of Rutaceae family commonly known as Bael or Bilwa, grows in tropical and subtropical region of South East Asia and India. All parts of the tree are used as herbal medicine in Ayurved, Unani and Siddha systems of medicine for the treatment of various ailments like dysentery, dyspepsia, chronic diarrhea. ${ }^{1,2}$ Soft drinks prepared from the fruit pulp are used in India to keep the body cool during summers. Aqueous extract of bael fruit has shown hypoglycemic effects in streptozotocin induced diabetes in rats when administered orally and intra peritoneally. ${ }^{3}$ Leaf extracts of $A$. marmelos are reported to have cardiotonic, hypoglycemic, antidyslipidemic, anticancer effects and also used to cure opthalmia, ulcers, dropsy, cholera and beri beri. The leaf extract was also reported to regenerate pancreatic islets in diabetic rats; although the mechanisms for these activities are not fully understood. ${ }^{1,4-6}$

Free radicals are generated in the body due to oxidative stress developed during normal metabolic processes or upon exposure to various environmental or chemical factors which subsequently damage the macromolecules like DNA, proteins and lipids. Oxidative stress is one of the contributing factors of various diseases like cancer and diabetes. ${ }^{7}$

Natural products have been reported to have stores of large amount of antioxidants other than Vitamin C, E and carotenoids. Antioxidants delay or prevent free radical catalyzed reactions. Various phenolic compounds and flavonoids are responsible for the antioxidant activity of medicinal plants. ${ }^{8} 9$ Therefore, it was thought worthwhile to evaluate antioxidant activity of $A$. marmelos leaf extract. In the present investigation, antioxidant activity of $A$. marmelos leaf extract was assessed using various methods.

\section{MATERIALS AND METHODS}

\section{Plant material}

The leaves of A. marmelos were collected from New Delhi India during the month of December. The leaves were shade dried for 20-25 days. The plant material was authenticated by Dr. Sunita Garg, Chief Scientist, Raw Materials Herbarium \& Museum, CSIR-NISCAIR, New Delhi, India and specimen was deposited in Raw Materials Herbarium \& Museum, CSIRNISCAIR, New Delhi, India.

\section{Preparation of Extracts}

The air dried leaves were powdered (about $350 \mathrm{gm}$ ) and extracted with $50 \%$ ethanol using Soxhlet apparatus. The extract was filtered through Whatmann filter paper and the filtrate was concentrated in Rotary evaporator. Dried extract was stored at $4^{\circ} \mathrm{C}$ and methanol soluble portion (AME) is used for further studies. The percentage yield of the extract was $20 \%$.

\section{Quantitative phytochemical analysis Total phenolic content (TPC)}

Total phenols were determined by Folin Ciocalteu reagent. ${ }^{10} 2 \mathrm{~mL}$ of the $1 \mathrm{mg} / \mathrm{mL}$ of AME was mixed with $2 \mathrm{ml}$ of Folin-Ciocalteu reagent, followed by addition of $2 \mathrm{~mL}$ of $7.5 \%$, w/v solution of sodium carbonate. The mixture was stirred and measured at $765 \mathrm{~nm}$ after keeping in the dark for $30 \mathrm{~min}$. A blank sample consisting of methanol and reagents was used as a reference. A sample color blank was examined using the AME and water to exclude the color interference of the AME. The results were expressed as $\mathrm{mg}$ of gallic acid equivalents per $100 \mathrm{~g}$ of dry weight (mg GAE/100 g DW), utilizing a calibration curve of gallic acid in a concentration range of $10-60 \mu \mathrm{g} / \mathrm{mL}$.

\section{Total flavonoid content (TFC)}

Aluminium chloride colorimetric method was used for flavonoids determination. ${ }^{11} 1 \mathrm{~mL}$ of $1 \mathrm{mg} / \mathrm{mL}$ AME was mixed with $4 \mathrm{~mL}$ of distilled water and $0.3 \mathrm{~mL}$ of $5 \%$ solution of sodium nitrite. After $5 \mathrm{~min}, 0.3 \mathrm{~mL}$ of $10 \%$ solution of aluminium chloride was added and followed by addition of $2 \mathrm{~mL}$ of $1 \mathrm{M}$ sodium hydroxide. The entire mixture was immediately diluted to $10 \mathrm{~mL}$ with distilled water. The mixture was mixed thoroughly and read at $510 \mathrm{~nm}$ against a blank. A calibration curve was plotted by using serial dilutions of quercetin solution at concentrations 20 to $100 \mathrm{mg} / \mathrm{mL}$ in methanol. The results were ex- 
pressed as mg of quercetin equivalent per $100 \mathrm{~g}$ of dry weight (mg QE/100 g DW).

\section{Antioxidant activity FRAP assay}

The FRAP assay was determined by modified method of Müller et al. (2011). ${ }^{12}$ The working FRAP solution was freshly prepared by mixing $300 \mathrm{mM}$ acetate buffer of $\mathrm{pH}$ 3.6,10 mM TPTZ (2,4,6-Tris(2-pyridyl)-striazine ) solution in $40 \mathrm{mM} \mathrm{HCl}$ and $20 \mathrm{mM}$ ferric chloride solution in a ratio of 10:1:1. The working solution was warmed at $37^{\circ} \mathrm{C}$ before use. An aliquot of $100 \mu \mathrm{L}$ of $1 \mathrm{mg} / \mathrm{mL}$ of AME was mixed with $3 \mathrm{~mL}$ FRAP solution. After $4 \mathrm{~min}$ of incubation at $37^{\circ} \mathrm{C}$, the absorbance was read at $593 \mathrm{~nm}$. A calibration curve was made by ferrous sulphate and results were expressed as $\mathrm{mM} \mathrm{Fe}^{2+}$ per $\mathrm{g}$ dried weight $\left(\mathrm{mM} \mathrm{Fe}^{2+} / \mathrm{g} \mathrm{DW}\right)$ from four determinations.

\section{DPPH radical scavenging activity}

DPPH radical scavenging activity was conducted according to the method described by Gülçin (2006), with some modifications. ${ }^{13}$ An aliquot of $4 \mathrm{~mL} 0.1 \mathrm{mM}$ DPPH radical in buffered methanol was mixed with $2 \mathrm{~mL}$ AME at different concentrations or methanol as negative control. The mixture was kept in dark for $30 \mathrm{~min}$ and then read at $517 \mathrm{~nm}$ with a blank contain only DPPH solution and methanol. The sample colour blank was examined containing AME and methanol to exclude the colour interference of sample extract. The DPPH radical-scavenging activity (\%) was calculated using Eq.(1).

$$
\text { Scavenging activity }(\%)=\frac{\left(\mathrm{A}_{\text {control }}-\mathrm{A}_{\text {sample }}\right)}{\left(\mathrm{A}_{\text {control }}\right)} \times 100
$$

Where, $A_{\text {sample }}$ is the absorbance in the presence of extracts, and $A_{\text {control }}$ is the absorbance of the control. ${ }^{13}$

\section{ABTS radical cation scavenging activity}

ABTS radical cation scavenging activity was assayed according to method of Re et al. (1999), with minor variation. ${ }^{14}$ The $\mathrm{ABTS}^{+}$solution was prepared by reacting $7 \mathrm{mM}$ ABTS solution and $2.45 \mathrm{mM}$ potassium persulfate (final concentration) in the dark for at least $16 \mathrm{~h}$ at room temperature. The solution was then diluted 65 times with phosphate

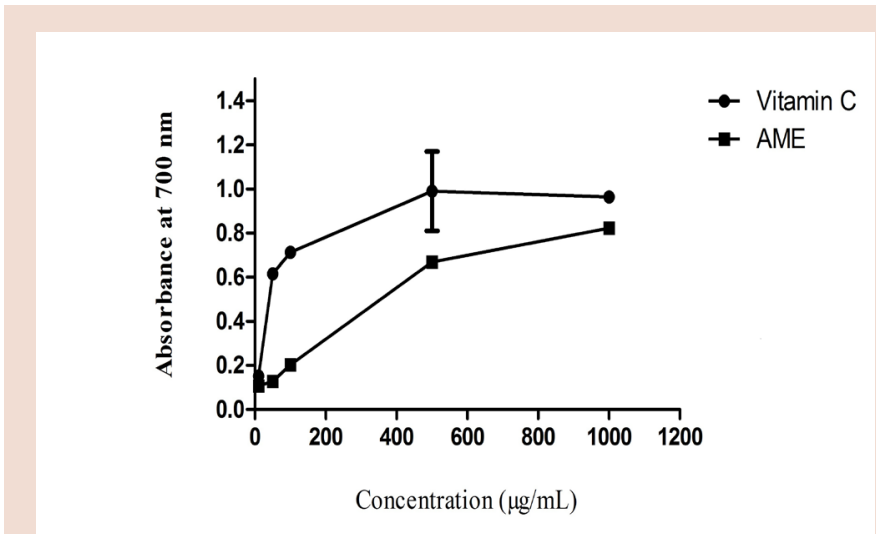

Figure 1: Reducing power of AME and vitamin C.

buffer of pH 7.4 to an absorbance of 0.759 at $728 \mathrm{~nm}$ as the working solution. An aliquot of $5 \mathrm{~mL}$ working solution was mixed with $50 \mu \mathrm{L}$ of $\mathrm{AME}$ at different concentrations and allowed to react at $30^{\circ} \mathrm{C}$ for $20 \mathrm{~min}$. A blank containing $\mathrm{ABTS}^{+}$working solution and ethanol was detected. The absorbance was measured at $734 \mathrm{~nm}$. The radical scavenging activity of the samples was calculated using Eq. (1).

\section{Reducing power}

The reducing power of AME was determined by the method of Zhang et al. (2009), with minor modifications..$^{15}$ Briefly, an aliquot of $1 \mathrm{~mL}$ AME at various concentrations was mixed with $1 \mathrm{~mL}$ of $1 \% \mathrm{w} / \mathrm{v}$ potassium ferricyanide in $0.2 \mathrm{M}$ PBS of $\mathrm{pH} 6.6$. The mixture was incubated at $50^{\circ} \mathrm{C}$ for $20 \mathrm{~min}$ and then added to $1 \mathrm{~mL}$ of $10 \% \mathrm{w} / \mathrm{v}$ trichloroacetic acid. This 3 $\mathrm{mL}$ mixture is diluted with equal amount of distilled water and the absorbance was measured at $710 \mathrm{~nm}$ after $30 \mathrm{~min}$. of adding $200 \mu \mathrm{L}$ of $0.1 \%$ $\mathrm{w} / \mathrm{v}$ ferric chloride. The blank contained all reagents except the sample extract.

\section{Statistical analysis}

All data were expressed as Mean \pm SD. The correlations between phytochemical contents and antioxidant activities were statistically evalu-

Table 1: TPC, TFC, FRAP value and IC ${ }_{50}$ values of DPPH, ABTS and reducing power of AME

\begin{tabular}{ccccccc}
\hline Sample & $\begin{array}{c}\mathrm{TOC} \\
(\mathrm{mg} \mathrm{GAE} / 100 \mathrm{~g} \\
\mathrm{DW})\end{array}$ & $\begin{array}{c}\mathrm{TFC}(\mathrm{mg} \\
\mathrm{QE} / 100 \mathrm{~g} \mathrm{DW})\end{array}$ & $\begin{array}{c}\mathrm{FRAP}(\mathrm{mM} \\
\left.\mathrm{Fe}^{2+} / \mathrm{g} \mathrm{DW}\right)\end{array}$ & $\begin{array}{c}\mathrm{DPPHIC}_{50} \\
(\mu \mathrm{g} / \mathrm{mL})\end{array}$ & $\begin{array}{c}\mathrm{ABTS} \mathrm{IC}_{50} \\
(\mu \mathrm{g} / \mathrm{mL})\end{array}$ & $\begin{array}{c}\text { Reducing } \\
\text { power }(\mu \mathrm{g} / \mathrm{mL})\end{array}$ \\
\hline AME & $1118.12 \pm 7919$ & $91467 \pm 118.51$ & $147.33 \pm 23.21$ & $160.47 \pm 8.51$ & $282.46 \pm 44.11$ & $475.42 \pm 25.95$ \\
$\begin{array}{c}\text { Vitamin } \\
\text { C }\end{array}$ & - & - & - & $11.70 \pm 0.013$ & $37.42 \pm 0.40$ & $42.99 \pm 4.65$ \\
\hline
\end{tabular}

Table 2: Pearson's correlation coefficients of TPC, TFC and antioxidant activities AME

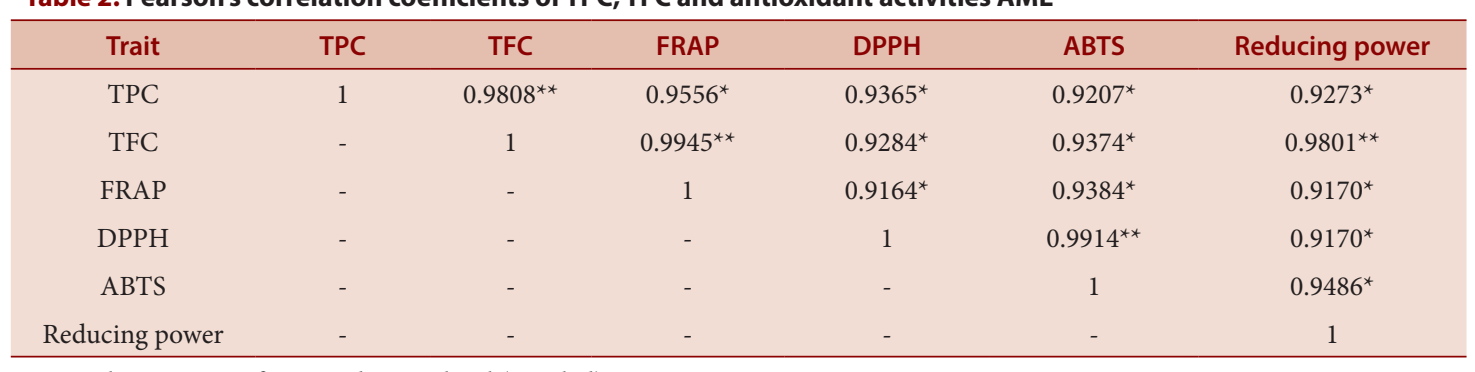

* Correlation is significant at the 0.05 level (2-tailed).

** Correlation is significant at the 0.01 level (2-tailed). 
ated by two tailed bivariate correlate analysis, and were indicated by Pearson's coefficient indexes and $\mathrm{p}<0.05$ was considered as statistically significant.

\section{RESULTS AND DISCUSSION}

TPC and TFC are used as indicators of overall antioxidant activity of the herbal drugs. ${ }^{16}$ Poly phenols have been recognized to show medicinal properties and exhibit physiological activity. ${ }^{7}$ The TPC of AME was tested by Folin-Ciocalteu method with gallic acid as standard. The TPC of the AME was found to be $1118.12 \pm 79.19 \mathrm{mg} \mathrm{GAE} / 100 \mathrm{~g}$ of dried material. The TPC over $500 \mathrm{mg} \mathrm{GAE} / 100 \mathrm{~g}$ is considered as a high category antioxidant activity. Flavonoids are hydroxyls containing secondary metabolites present in plants and exhibit free radical scavenging activities. ${ }^{17} \mathrm{In}$ this study, TFC of AME was found to be $914.67 \pm 118.51 \mathrm{mg}$ of QE/100 g of dried material. The results were comparable with the reported results of TPC of the fruit pulp of A. marmelos. ${ }^{3}$

Antioxidant activity of AME was evaluated by different detection methods. Primary antioxidants have been shown to react against the oxidative stress by breaking chain reaction or by scavenging free radicals. While, secondary antioxidants deactivate metals, inhibit the breakdown of lipid peroxides, regenerate primary antioxidants, and quench singlet oxygen. ${ }^{18}$ Therefore, various chemical based assay methods have been developed and attuned for the detection of antioxidant activities. ${ }^{19,14}$

FRAP assay quantitate the ability of an antioxidant to reduce the $\mathrm{Fe}^{3+}$ / tripyridyl-s-triazine complex. ${ }^{12}$ As shown in Table 1, AME had FRAP values of over $147 \mathrm{mM} \mathrm{Fe}^{2+} / \mathrm{g}$ DW. The reducing capacity of a compound may serve as a significant indicator of its potential antioxidant activity. The DPPH and ABTS method focus on the non-specific radicals existed in the reaction system. The DPPH method is based on the reduction of $\mathrm{DPPH} \bullet$ into diphenyl picryl hydrazine in the presence of a hydrogen donating antioxidant. AME reduces the colour of DPPH due to its hydrogen donating ability. ${ }^{7}$ The $\mathrm{IC}_{50}$ values of DPPH and ABTS radical scavenging activities were $160.47 \pm 8.51 \mu \mathrm{g} / \mathrm{mL}$ and $282.46 \pm 44.11 \mu \mathrm{g} / \mathrm{mL}$, respectively as shown in Table 1 . The total reducing power serves as a significant indicator of the potential antioxidant capacity, and is expressed as the increased absorbance of the reaction mixture at $710 \mathrm{~nm} .{ }^{15}$ Figure 1 shows the reduction of $\mathrm{Fe}^{3+}$ to $\mathrm{Fe}^{2+}$ in the presence of AME. The $\mathrm{IC}_{50}$ value is defined as the effective concentration at which the absorbance was 0.5. As displayed in the Figure 1, the absorbance of the Vitamin C dramatically increased in a dose dependent-manner while AME also reduce $\mathrm{Fe}^{3+}$ in a dose dependent manner.

The TPC and TFC of herbal drugs have been proved to be positively correlated with their antioxidant activities. ${ }^{16,17}$ Table 2 lists the Pearson's coefficients between TPC, TFC and various antioxidant capacities. The TPC showed a high positive correlation with TFC, FRAP, DPPH, ABTS cation scavenging and reducing power $\left(\mathrm{r}^{2}=0.9808^{* *}, 0.9556^{*}, 0.9365^{*}\right.$, $0.9207^{*}$ and $0.9273^{*}$, respectively). The correlation coefficients of the TFC to the FRAP, DPPH, ABTS cation scavenging and reducing power were $0.9945^{* *}, 0.9286^{*}, 0.9376^{*}$ and $0.9801^{*}$, respectively.

The antioxidant constituents provide a fillip to the antioxidant defense mechanism in cancer and increase the uptake of glucose by muscles by modulating lipid peroxidation, scavenging free radicals and reducing the generation of reactive oxygen species (ROS). ${ }^{3,6}$

\section{CONCLUSION}

The antioxidative effect of the AME is ascribed to the free radical scavenging property due to the presence of phenolics and flavonoids. Hence, the hypoglycemic and anticancer effect of leaves of $A$. marmelos could be credited to its antioxidant property. Further studies are required to identify the specific active principles of the plant for this significant antioxidant effect.

\section{ACKNOWLEDGEMENT}

None.

\section{CONFLICT OF INTEREST}

The author declare no conflict of interest.

\section{ABBREVIATION USED}

AME: Methanolic leaf extract of Aegle marmelos; TPC: Total phenolic content; GAE: Gallic acid equivalent; DW: Dried weight; TFC: Total flavonoid content; QE: Quercetin equivalent; FRAP: Ferric reducing ability of plasma; DPPH: 1,1-Diphenyl-2-picrylhydrazyl; ABTS: 2,2'-azino-bis(3-ethylbenzothiazoline-6-sulphonic acid); ROS: Reactive oxygen species.

\section{REFERENCES}

1. Sankeshi V, Kumar PA, Naik RR, Sridhar G, Kumar MP, Gopal VH, et al. Inhibition of aldose reductase by Aegle marmelos and its protective role in diabetic cataract. J Ethnopharmacol. 2013;149(1): 215-21.

2. Reddy PV, Sahana N, Urooj A. Antioxidant activity of Aegle marmelos and Psidium guajava leaves. IJMAP. 2012;2(1):155-60.

3. Prathapan A, Krishna MS, Nisha VM, Sundaresan A, Raghu KG. Polyphenol rich fruit pulp of Aegle marmelos (L.) Correa exhibits nutraceutical properties to down regulate diabetic complications-An in vitro study. Food Res Int. 2012;48(2):690-5

4. Karunanayake EH, Welihinda J, Sirimanne SR, Adorai GS. Oral hypogly caemic activity of some medicinal plants of Sri Lanka. J Ethnopharmacol. 1984; $11(2): 223-31$

5. Seema PV, Sudha B, Padayatti PS, Abraham A, Raghu KG, Paulose CS. Kinetic studies of purified malate dehydrogenase in liver of streptozotocin-diabetic rats and the effect of leaf extract of Aegle marmelose (L) Correa ex Roxb. Indian J Ex Biol. 1996;34:600-2.

6. Chockalingam V, Kadali SS, Gnanasambantham P. Antiproliferative and antioxidant activity of Aegle marmelos (Linn.) leaves in Dalton's Lymphoma Ascites transplanted mice. Indian J Pharmacol 2012;44(2):225-9.

7. Rajan S, Gokila M, Jency P, Brindha P, Sujatha RK. Antioxidant and phytochemical properties of Aegle marmelos fruit pulp. Int J Curr Pharm Res. $2011 ; 3(2): 65-70$

8. Pietta P, Simonetti P, Mauri P. Antioxidant activity of selected medicinal plants J Agric Food Chem. 1998;46(11):4487-90.

9. Barlow SM. Toxicological aspects of antioxidants used as food additives. In: Hudson BJF, editor. Food antioxidants. $1^{\text {st }}$ ed. London: Elsevier. 1990;253-307.

10. McDonald S, Prenzler PD, Antolovich M, Robards K. Phenolic content and antioxidant activity of olive extracts. Food Chem. 2001;73(1):73-84.

11. Chang CC, Yang MH, Wen HM, Chern JC. Estimation of total flavonoid content in propolis by two complementary colorimetric methods. J Food Drug Anal. 2002;10(3):178-82.

12. Müller L, Fröhlich K, Böhm V. Comparative antioxidant activities of carotenoids measured by ferric reducing antioxidant power (FRAP), ABTS bleaching assay $(\alpha \mathrm{TEAC}), \mathrm{DPPH}$ assay and peroxyl radical scavenging assay. Food Chem. 2011;129(1):139-48.

13. Gülçin I. Antioxidant activity of caffeic acid (3, 4-dihydroxycinnamic acid). Toxicol. 2006;217(2):213-20

14. Re R, Pellegrini N, Proteggente, A, Pannala A, Yang M, Rice-Evans C. Antioxidant activity applying an improved ABTS radical cation decolorization assay. Free Radic Biol Med. 1999;26(9):1231-7.

15. Zhang QF, Zhang ZR, Cheung HY. Antioxidant activity of Rhizoma Smilacis Glabrae extracts and its key constituent-astilbin. Food Chem. 2009;115(1):297-303.

16. Velioglu YS, Mazza G, Gao L, Oomah BD. Antioxidant activity and total phenolics in selected fruits, vegetables, and grain products. J Agric Food Chem. 1998;46(10):4113-7.

17. Cai $Y$, Luo Q, Sun M, Corke $H$. Antioxidant activity and phenolic compounds of 112 traditional Chinese medicinal plants associated with anticancer. Life Sciences. 2004;74(17):2157-84.

18. Gordon $\mathrm{MH}$. The mechanism of antioxidant action in vitro. Hudson BJF, editor In: Food antioxidants. $1^{\text {st }}$ ed. London: Elsevier. 1990;1-18.

19. Moein MR, Moein S, Ahmadizadeh S. Radical scavenging and reducing power of Salvia mirzayanii subfractions. Molecules. 2008;13(11):2804-13. 


\section{PICTORIAL ABSTRACT}

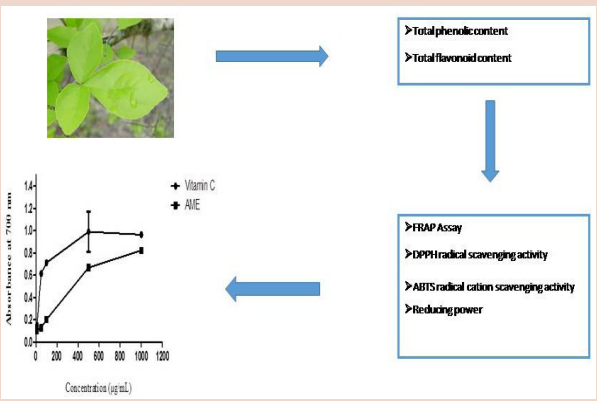

\section{SUMMARY}

- Free radicals produce oxidative stress in the body which could be one of the contributing factors of various diseases like cancer and diabetes.

- Antioxidant present in natural products prevent free radicals generated oxidative stress.

- Leaf extract of Aegle marmelos have phenolic and flavonoids contents.

- Leaf extract of $A$. marmelos have shown free radical scavenging and antioxidant property.

- Significant correlation is seen in phenolic content, flavonoid content and antioxidant activity of leaf extract of $A$. marmelos.

\section{ABOUT AUTHOR}

Sachin Kumar: Is a doctoral student at University of Delhi, India. He has obtained his Masters in Pharmacology and Toxicology from National Institute of Pharmaceutical Education and Research (NIPER), Guwahati, India. His doctoral research focused on the evaluation of antioxidant activity and cytotoxicity of Indian medicinal plants and also quantification of active constituents with HPLC and GC-MS 